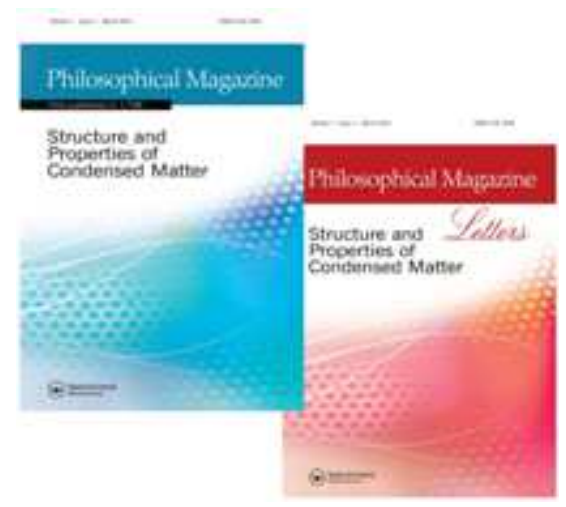

\title{
Roles of local He concentration and Si sample orientation on cavity growth in amorphous silicon
}

\begin{tabular}{|c|c|}
\hline Journal: & Philosophical Magazine \& Philosophical Magazine Letters \\
\hline Manuscript ID: & TPHM-10-Dec-0505.R2 \\
\hline Journal Selection: & Philosophical Magazine \\
\hline $\begin{array}{l}\text { Date Submitted by the } \\
\text { Author: }\end{array}$ & 05-Aug-2011 \\
\hline Complete List of Authors: & $\begin{array}{l}\text { Canino, Mariaconcetta; Aix-Marseille universités, laboratoire IM2NP; } \\
\text { Consiglio Nazionale delle Ricerche, Istituto per la microelettronica e } \\
\text { i microsistemi } \\
\text { Regula, Gabrielle; Aix-Marseille universités, laboratoire IM2NP } \\
\text { Xu, Ming; Aix-Marseille universités, laboratoire IM2NP; CEMTHI- } \\
\text { UPR3079 CNRS; } 3 \text { CEMTHI-UPR3079 CNRS; SIMIT } \\
\text { Ntsoenzok, Esidor; CEMTHI-UPR3079 CNRS; Université d'Orléans } \\
\text { Lancin, Maryse; CNRS (UMR 6242), laboratoire IM2NP } \\
\text { Barthe, Marie-France; CEMTHI-UPR3079 CNRS } \\
\text { Sauvage, Thierry; CEMTHI-UPR3079 CNRS } \\
\text { Oliviero, Erwan; Université de Paris 11, CSNSM } \\
\text { Pichaud, Bernard; Aix-Marseille Université, laboratoire IM2NP }\end{array}$ \\
\hline Keywords: & $\begin{array}{l}\text { a-Si, cavities, ion irradiation, recrystallization, positron annihilation, } \\
\text { transmission electron microscopy }\end{array}$ \\
\hline Keywords (user supplied): & \\
\hline
\end{tabular}

\section{SCHOLARONE Manuscripts}




\section{Roles of local He concentration and Si sample orientation on cavity growth in amorphous silicon}

Mariaconcetta Canino ${ }^{1,2}$, Gabrielle Regula ${ }^{1}$, Ming $\mathrm{Xu}^{1,3,4}$, Esidor Ntsoenzok $^{3,5}$, M. Lancin ${ }^{1}$, Marie-France Barthe ${ }^{3}$, Thierry Sauvage ${ }^{3}$, E. Oliviero $^{6}$, Bernard Pichaud ${ }^{1}$

${ }^{1}$ Aix-Marseille Université, IM2NP, CNRS (UMR 6242), av. Escadrille Normandie Niemen, F-13397 Marseille Cedex 20

${ }^{2}$ CNR-IMM sez. Bo, Via P. Gobetti 101, I-40129 Bologna

${ }^{3}$ CEMTHI-UPR3079 CNRS Site Cyclotron, 3A rue de la Férolerie F-45071 Orléans Cedex 2

${ }^{4}$ SIMIT 865 Changning Road, CN-200050 Shanghai

${ }^{5}$ Université d'Orléans, Avenue du Parc Floral, BP 6749, F-45067 Orléans cedex2

${ }^{6}$ Université de Paris 11, CSNSM Bâtiments 104 et 108, F-91405 Orsay Campus 


\section{Roles of local He concentration and Si sample orientation on cavity growth in amorphous silicon}

(111)- and (100)-oriented $\mathrm{Si}$ samples are implanted with $\mathrm{Si}^{+}$ions at $1 \mathrm{MeV}$ to a dose of $1 \times 10^{16} \mathrm{~cm}^{-2}$ and with $5 \times 10^{16} \mathrm{He}^{+} \mathrm{cm}^{-2}$ at $10 \mathrm{keV}$ or $50 \mathrm{keV}$ and eventually annealed in the $800{ }^{\circ} \mathrm{C}-1000{ }^{\circ} \mathrm{C}$ temperature range. Sample characterization is carried out by cross section transmission electron microscopy, positron annihilation spectroscopy, and nuclear reaction analysis. In addition to the formation of $\mathrm{He}$ bubbles at the projected range of $\mathrm{He}$, bubbles are observed after solid phase epitaxial growth (SPEG) of the embedded amorphous Si layer. The He threshold concentration required to get thermally stable bubbles in amorphised $\mathrm{Si}$ is between one and four orders of magnitude lower than in c-Si. Since bubble formation and growth take place in the a-Si phase, the interaction with SPEG during annealing is studied by considering (100) and (111) Si. Both the SPEG velocity and the resulting defects play a role on bubble spatial distribution and size, resulting in bigger bubbles in (111) Si with respect to (100) Si.

Keywords: amorphous silicon; cavities; ion irradiation; recrystallization; positron annihilation; transmission electron microscopy

\section{Introduction}

Cavities can be formed in crystalline $\mathrm{Si}$ (c-Si) after gas ion implantation, provided that a local threshold concentration of gas is reached, that is $\mathrm{He}_{\mathrm{lim}}=3.5 \times 10^{20} \mathrm{~cm}^{-3}$ in the case of He [1]. The role of He threshold concentration in vacancy (V) rich areas has still to be addressed: it can indicate either that the early stage of cavity formation results from He precipitation, or that the ratio between $\mathrm{V}$ and $\mathrm{He}$ levels, both depending on $\mathrm{He}^{+}$implantation dose, flux [2] and temperature, is a major parameter for helium-vacancy cluster $\left(\mathrm{He}_{\mathrm{n}} \mathrm{V}_{\mathrm{m}}\right)$ evolution $[3,4]$.

Bubble/cavity evolution upon classic thermal treatments has been intensively studied. Crucial phenomena, i.e. He desorption [5] and transition of He-related defects from platelets to bubbles/cavities [6], occur during annealing at temperatures between $400^{\circ} \mathrm{C}$ and $600^{\circ} \mathrm{C}$. In multi $\mathrm{He}^{+}$implanted samples in the $\mathrm{keV}$ range the cavity size starts changing at $700^{\circ} \mathrm{C}$ [7] until an equilibrium distribution is reached at $800^{\circ} \mathrm{C}-900^{\circ} \mathrm{C}$ [6]. A more recent model [8] predicts 
formation of nano-sized voids during rapid thermal processes in as grown $\mathrm{Si}$ wafers. It accounts for high temperature cluster configurational entropy which lowers the free energy of $\mathrm{V}$ cluster formation, leading to lower super saturation thresholds for $\mathrm{V}$ aggregation and more rapid aggregation kinetics. Experimental evidence of nano-sized voids between $\mathrm{R}_{\mathrm{p}}(\mathrm{He})$ and the sample surface is given in $[9,10,11]$. They anneal out at temperatures higher than $800^{\circ} \mathrm{C}-900^{\circ} \mathrm{C}$. V aggregation in thermally unstable clusters takes place even after high dose $\mathrm{Si}^{+}$or $\mathrm{F}^{+}$ion implantation without the stabilization of $\mathrm{He}$ $[12,13]$

Even less is known about cavity formation and evolution in amorphous silicon (a-Si), since Si recrystallization by solid phase epitaxial growth (SPEG) occurs at $500{ }^{\circ} \mathrm{C}$, which is in the temperature range of cavity growth. In particular, the local He threshold concentration to form cavities in a-Si is not determined yet. It is known that in the absence of He, SPEG of a-Si layers in cSi proceeds by the movement of the a-Si/c-Si interface inside the a-Si phase, with the crystalline layer acting as a template for reassembling of Si-Si bounds $[14,15,16]$. The presence of gas and bubbles is thought either to increase the probability of bonding mistakes, leading to SPEG in the polycrystalline form (p-Si) [17], or to act as nucleation site for microtwins, which in turn are responsible for p-Si growth [14].

In this work, the generation of bubble/cavities in (100) and (111) $\mathrm{Si}$ amorphized by $\mathrm{Si}^{+}$implantation is checked as a function of the position of the $\mathrm{He}^{+}$implantation peak with respect to the amorphous layer.

\section{Experimental}


Two sets of Si wafers different in surface orientation are used: (111) Si samples are ntype epitaxial layers, $175 \mu \mathrm{m}$ thick with donor concentration equal to $10^{13} \mathrm{~cm}^{-3}$, grown on highly doped n-type CZ substrates; (100) Si samples are n-type CZ wafers $525 \mu \mathrm{m}$ thick with donor concentration equal to $10^{15} \mathrm{~cm}^{-3}$. A sequence of ion implantation processes is performed, beginning by the deepest to the shallowest. Energy and dose of the implanted-species are chosen after computing their concentration profiles by transport range of ions in matter (TRIM) simulations [18]. First $1 \mathrm{MeV} \mathrm{Si}^{+}$ions are implanted to a dose of $1 \times 10^{16} \mathrm{~cm}^{-2}$, beyond the threshold value for Si amorphization (15eV/atom) [19]. The Si projected range, $\mathrm{R}_{\mathrm{p}}(\mathrm{Si})$, is calculated to be $1120 \mathrm{~nm}$. Second, ${ }^{4} \mathrm{He}^{+}$ion implantation at a dose of $5 \times 10^{16} \mathrm{~cm}^{-2}$ is performed on some samples either at $10 \mathrm{keV}$ or $50 \mathrm{keV}$. The $\mathrm{R}_{\mathrm{p}}(\mathrm{He})$ for these energy values is $110 \mathrm{~nm}$ and $420 \mathrm{~nm}$ respectively. The dose is chosen in order to get a local He concentration higher than $\mathrm{He}_{\mathrm{lim}}$ at $\mathrm{R}_{\mathrm{p}}(\mathrm{He})$. To allow nuclear reaction analysis (NRA) measurements to be carried out, ${ }^{3} \mathrm{He}^{+}$instead of ${ }^{4} \mathrm{He}^{+}$is used for gas implantation at energy and doses determined by TRIM in order to have a profile similar to the ${ }^{4} \mathrm{He}^{+}$one for an implantation at $50 \mathrm{keV}$ with $5 \times 10^{16}{ }^{4} \mathrm{He}^{+} \mathrm{cm}^{-2}$ (i.e. $60 \mathrm{keV}$ and $2.5 \times 10^{16}{ }^{3} \mathrm{He}^{+} \mathrm{cm}^{-2}$ respectively). Only ${ }^{4} \mathrm{He}^{+}$will be referred as $\mathrm{He}^{+}$in this work. All samples, named with roman numbers, underwent either furnace annealing at $800^{\circ} \mathrm{C}$ for one hour in $\mathrm{Ar}$ or a rapid thermal annealing (RTA) at $900{ }^{\circ} \mathrm{C}$ or $1000{ }^{\circ} \mathrm{C}$ for $20 \mathrm{~s}$ in $\mathrm{N}_{2}$. Ion implantation and annealing conditions are summarized in Table 1.

Sample characterization is performed by cross-section transmission electron microscopy (XTEM), by positron annihilation spectroscopy (PAS) to detect open volumes and vacancy type defects, and by NRA to measure He concentration profiles. For XTEM analyses, thin foils are prepared by focused ion beam (FIB). Consequently, little amorphization (about $50 \mathrm{~nm}$ in depth) of the sample surface 
cannot be avoided when protecting the sample surface by ion-assisted Pt organometallic alloy deposition. The samples are observed with a Jeol 2010 field emission gun and/or a Tecnai $\mathrm{G}$ twin $\left(\mathrm{LaB}_{6}\right)$ microscopes. PAS spectra are performed by mean of a positron accelerator providing energies ranging from $0.5 \mathrm{keV}$ to $25 \mathrm{keV}$, thus exploring the first three microns under the sample surface.

\section{Results}

$1 \mathrm{MeV} \mathrm{Si}^{+}$implantation and subsequent $10 \mathrm{keV}$ or $50 \mathrm{keV} \mathrm{He}^{+}$implantation are performed in both (111)- and (100)-oriented wafers. Figures 1a and 1b show XTEM micrographs of samples III-900 and IV-900, respectively. In sample III-900 (Figure 1a) a polycrystalline layer ( $\mathrm{p}-\mathrm{Si}$ ) is observed, as it is demonstrated by its diffraction pattern, corresponding in depth and width to the a-Si phase in as implanted samples delimited by black solid lines. Microtwins are also present in the $\mathrm{p}-\mathrm{Si}$, as well as end of range (EOR) defects at its deeper border, whose position is marked by an arrow. In sample IV-900 (Figure 1b) there are dislocation loops and $\{311\}$ defects extending to $2.5 \mu \mathrm{m}$ in depth. As expected, a band of bubbles/cavities is formed at $\mathrm{R}_{\mathrm{p}}(\mathrm{He})$ in both samples, but also a band of bubbles/cavities, with increasing diameter, is observed starting from the shallower a-Si/c-Si recrystallized interface and extending for about $500 \mathrm{~nm}$ towards the sample depth. This region is delimited by white dashed lines in Figure 1b. In III-900, bubble/cavity diameter is as big as $50 \mathrm{~nm}$. In the (100)-oriented sample (IV-900), it spans from $2.5 \mathrm{~nm}$ to $20 \mathrm{~nm}$ that makes them hardly visible at low magnification. The inset in the dotted square of Figure $1 \mathrm{~b}$ represents a zoom of the bubble/cavity layer, shown in Figure 1c. Solely the deep $\mathrm{He}^{+}$implantation allows bubbles/cavities at $\mathrm{R}_{\mathrm{p}}(\mathrm{Si})$ to be observed after high temperature annealing.

Bubble/cavity formation near $\mathrm{R}_{\mathrm{p}}(\mathrm{Si})$ is the main concern of this study, since there, He concentration must be much lower than $\mathrm{He}_{\mathrm{lim}}$ to form cavities in c-Si, as 
determined by NRA (see Figure 2). These measurements are performed in order to check the hypothesis of He diffusion towards $\mathrm{R}_{\mathrm{p}}(\mathrm{Si})$ during $\mathrm{He}^{+}$implantation and annealing. He concentration profile is measured in a sample similar to sample III1000, implanted with ${ }^{3} \mathrm{He}^{+}$. Though little diffusion towards the sample depth can be detected, He does not undergo any long range diffusion. The picture also reports the locations of the SPEG area, indicated by broken lines and the region where $\mathrm{He}^{+}$and $\mathrm{Si}^{+}$implantation related bubbles/cavities are observed, indicated by dotted and dashed lines respectively. The peak of He concentration is located just deeper than the bubbles/cavities at $\mathrm{R}_{\mathrm{p}}(\mathrm{He})$. At the shallower border of the porous region at $\mathrm{R}_{\mathrm{p}}(\mathrm{Si}) \mathrm{He}$ concentration spans from $2.5 \times 10^{20} \mathrm{~cm}^{-3}$ (after annealing) to $4 \times 10^{20} \mathrm{~cm}^{-3}$ (before annealing). The extrapolation of He levels at the deeper border of the porous recrystallized area is in the $3 \times 10^{16} \mathrm{~cm}^{-3}-2 \times 10^{20} \mathrm{~cm}^{-3}$ range respectively before and after annealing. Since the measured He dose before and after annealing are $(4.7 \pm 0.3)$ $\times 10^{16} \mathrm{~cm}^{-2}$ and $(4.5 \pm 0.3) \times 10^{16} \mathrm{~cm}^{-2}$ respectively, it is assumed that no He desorption takes place. Hence, we are actually in presence of bubbles (i.e. cavities filled with $\mathrm{He}$ ) in a zone corresponding to intersections between He profiles before and after annealing.

PAS spectra carried out in III and III-1000, together with a $\mathrm{He}^{+}$implanted sample, II-800, are shown in Figures 3a and 3b. An increase of the shape S(E) signal with respect to the virgin reference wafer is detected in all cases, indicating the presence of vacancy-type defects. As shown in Figure 3b, while sample III displays a quasi-homogenous shape S(E) signal, two peaks are detected in sample III-1000. They are located at $8 \mathrm{keV}$ and $10 \mathrm{keV}$ positron energy, corresponding to about 400 $\mathrm{nm}$ and $700 \mathrm{~nm}$ in sample depth. In the reference sample, solely implanted with $50 \mathrm{keV} \mathrm{He}^{+}$, only one peak is detected near the surface (Figure 3a) . The slight 
difference in energy of the shallow $\mathrm{S}(\mathrm{E})$ peaks detected in samples II-800 and III1000 is likely due to different defects produced by mono- and double implantation, as well as by different annealing conditions. As shown by Figure 3c, reporting the measured annihilation probability $\mathrm{S}$ as a function of the wing probability (W) parameter together with the trap signatures of $\mathrm{V}_{2}$ and cavities, solely $\mathrm{V}_{2}$ are detected in as-implanted sample (III), whereas sample III-1000 only contains cavities, demonstrating that the second peak is linked to cavities as well.

\section{Discussion}

Two bands of cavities are detected by XTEM, both at $\mathrm{R}_{\mathrm{p}}(\mathrm{He})$ and $\mathrm{R}_{\mathrm{p}}(\mathrm{Si})$, whatever the surface orientation, providing that $\mathrm{R}_{\mathrm{p}}(\mathrm{He})$ is the closer to $\mathrm{R}_{\mathrm{p}}(\mathrm{Si})$. On the ground of NRA measurements, cavities turn out to be bubbles, i.e. filled with He. Comparison between PAS spectra obtained on double-implanted samples and $\mathrm{He}^{+}$ implanted samples indicates that the layer of bubbles at $\mathrm{R}_{\mathrm{p}}(\mathrm{Si})$ is induced by $\mathrm{Si}^{+}$ion implantation defects, likely stabilized by He. Indeed, PAS measurements carried out on III-1000 (Figure 3b), reveal a pair of peaks in the spectrum which can be attributed to the bubble layer at $\mathrm{R}_{\mathrm{p}}(\mathrm{He})$ and to the $\mathrm{p}$-Si layer containing many types of defects including bigger bubbles, whereas single $\mathrm{He}^{+}$implantation (sample II-800, Figure 3a) produces only one peak located at about $400 \mathrm{~nm}$ in depth, related to cavities at $\mathrm{R}_{\mathrm{p}}(\mathrm{He})$. According to NRA measurements on $\mathrm{Si}^{+}$and ${ }^{3} \mathrm{He}^{+}$implanted wafer (Figure 2), He threshold concentration to form cavities in a-Si is speculated to be far lower than the one required in $\mathrm{c}-\mathrm{Si}$, which is reasonable, considering the higher stability of Vs in a-Si with respect to c-Si, and in agreement with Gandy [14]. It is worth noting that in the c-Si layer (samples V-800, V-900 and V-1000, not shown) bubbles are detected only at $\mathrm{R}_{\mathrm{p}}(\mathrm{He})$. This suggests that either the $\mathrm{Si}^{+}$implantation defects or the stability of Vs in the a-Si phase (or both) helps bubble formation at $\mathrm{R}_{\mathrm{p}}(\mathrm{Si})$. 
Nevertheless the role a rapid annealing in easing bubble/cavity formation cannot be ruled out, especially concerning the remaining of He in the defected area. However, it is not the key parameter, since i) cavities could be observed in samples annealed in a conventional furnace for 2 hours (I-800) and ii) cavities are observed, if any, only at $\mathrm{R}_{\mathrm{p}}(\mathrm{Si})$ in 10 s-annealed samples and not elsewhere.

By considering Figure 1, it is striking that crystal orientation of the a-Si/c-Si interface plays a role on bubble size. Indeed, it is known $[20,14]$ that microtwins are formed during SPEG of $\{111\}$ a-Si/c-Si interfaces only. Thus, grain boundaries can trap Is, which hinders I-V recombination intra grains. The consequence of the formation and the presence of these "V protection walls" is the formation of much bigger bubbles in (111)-oriented samples with respect to (100) ones. Nevertheless, whatever the crystal orientation, bubbles increase in size towards the sample depth. This, together with the bigger bubble size observed in (111) Si, in which SPEG proceeds at lower speed [20], indicates that bubble formation and growth occur in a$\mathrm{Si}$, as bubble size is proportional to the time spent by the bubble in the a-Si phase. Furthermore, a higher amount of vacancies is likely available for bubble growth near the middle of the SPEG region, since Vs are dragged there by the moving a-Si/c-Si interfaces, in order to stay in the amorphous phase, so that deeper cavities are bigger.

The importance of I trapping at microtwins is confirmed by considering that thermally unstable nanovoid formation in highly damaged amorphised (111) Si takes place even without He [12]. Conversely, XTEM observations of (100) samples that underwent the same processes except an additional shallow $\mathrm{He}^{+}$implantation (V-800), do not reveal any cavities at the $\mathrm{R}_{\mathrm{p}}(\mathrm{Si})$. In this experiment, $\mathrm{R}_{\mathrm{p}}(\mathrm{He})$ is too close to the sample surface or it is too far from $\mathrm{R}_{\mathrm{p}}(\mathrm{Si})$ with respect to He diffusion length, preventing He stabilization of Vs before they anneal out with Is. 


\section{Conclusion}

Bubbles are formed at the intersection of a buried a-Si layer, produced by self ion implantation, and of the tail of an implanted He profile, having its peak in the shallower c-Si region. The He threshold concentration required to get thermally stable bubbles in amorphized $\mathrm{Si}$ is between one and four orders of magnitude lower than in c-Si. Bubble formation and growth take place in the a-Si phase. Both the SPEG velocity and the resulting defects play a role on bubble size, resulting in easier bubble growth in (111) Si.

\section{Acknowledgements}

This work was granted by ANR French organization through the contract "Nanocafon" NT05-2-42001. The authors would like to thank L. Ehouarne for RTA performances at IM2NP and C. Dominici for his availability.

\section{References}

[1] V. Raineri, P. G. Fallica, G. Percolla, A. Battaglia, M. Barbagallo and S. U. Campisano, J. Appl. Phys. 78 (1995) p. 3727.

[2] S. Godey Ph.D. thesis, University of Orleans, France, 1999.

[3] M.S. Abd E1 Keriem, D.P. van der Werf, and F. Pleiter Hyperfine Interactions 79 (1993) p. 787.

[4] G.F. Cerofolini, F. Corni, S. Frabboni, C. Nobili, G. Ottaviani and R. Tonini, Mat. Sci. Eng. B 27 (2000) p.1.

[5] V. Raineri, Mat. Sci Eng. B 73 (2000) p. 47.

[6] R. Tonini, F. Corni, S. Frabboni, G. Ottaviani,and G.F. Cerofolini, J. Appl. Phys. 84 (1998) p. 4802.

[7] M. Dumont, G. Regula, M.-V. Coulet, M. F. Beaufort, E. Ntsoenzok, and B. Pichaud, to be published.

[8] T. A. Frewen and T. Sinno, Appl. Phys. Lett. 89 (2006) p. 191903.

[9] V. Raineri, M. Saggio and E. Rimini, J. Mat. Res. Soc. 15 (2000) 1449.

[10] A. Peeva, R. Koegler and W. Skorupa, Nucl. Istr. Meth. Phys Res. B 206 (2003) 71.

[11] S. Mirabella, E. Bruno, F. Priolo, F. Giannazzo, C. Bongiorno, V. Raineri, E. Napolitani and A. Carnera, Appl. Phys. Lett. 88 (2006) 191910.

[12] M. Canino, G. Regula, M. Lancin, M. Xu, B. Pichaud, E. Ntzoenzok and M.F. Barthe Mat Sci Eng. B, 159-160 (2009) 153.

[13] S. Boninelli, A. Claverie, G. Impellizzeri, S. Mirabella, F. Priolo, E. Napolitani and F. Cristiano, Appl. Phys. Lett. 89, (2006) 171916.

[14] A.S. Gandy, PhD. thesis, University of Salford, Great Britain, 2008. 
[15] R. Drosd, and J. Washburn, J. Appl. Phys 53 (1982) p. 397.

[16] J. Narayan, J. Appl. Phys. 53 (1982) p. 8607.

[17] P. Revesz, M. Wittmer, J. Roth, and J. W. Mayer, J. Appl. Phys. 49 (1978) p. 5199.

[18] J.F. Ziegler, J.P. Biersack and U. Littmark, The Stopping and Range of Ions in Solids, Pergamon, New York, 1985.

[19] N. E. B. Cowern, A. J. Smith, B. Colombeau, R. Gwilliam, B. J. Sealy and E. J. H. Collart, IEEE, Electron Devices Meeting (2005).

[20] L. Csepregi, J. W. Mayer, and T. W. Sigmon, Appl. Phys. Lett. 29 (1976) p. 92.

Table 1. Sample name, wafer orientation, ion implantation details $\mathrm{Sii}^{+}$and $\mathrm{He}^{+}$ion implantation energy and dose), annealing details (temperature and time). The last column indicates whether (Yes/No) cavities are observed by XTEM after annealing, and their position. In all $\mathrm{He}^{+}$implanted samples cavities are observed at $\mathrm{R}_{\mathrm{p}}(\mathrm{He})$.

\begin{tabular}{|c|c|c|c|c|c|c|c|c|}
\hline & \multirow{2}{*}{$\begin{array}{l}\text { Crystal } \\
\text { surface }\end{array}$} & \multicolumn{2}{|c|}{ Si implantation } & \multicolumn{2}{|c|}{ He implantation } & \multicolumn{3}{|c|}{ Annealing } \\
\hline & & $\mathrm{E}(\mathrm{MeV})$ & Dose $\left(\mathrm{cm}^{-2}\right)$ & $\mathrm{E}(\mathrm{keV})$ & Dose $\left(\mathrm{cm}^{-2}\right)$ & $\mathrm{T}\left({ }^{\circ} \mathrm{C}\right)$ & $\mathrm{t}(\mathrm{s})$ & $\begin{array}{l}\text { Cavity } \\
\text { position }\end{array}$ \\
\hline I & (111) & 1 & $1 \times 10^{16}$ & & & - & - & $\mathrm{N}$ \\
\hline $\mathrm{I}-800$ & (111) & 1 & $1 \times 10^{16}$ & & & 800 & 3600 & Y surface \\
\hline I-1000 & (111) & 1 & $1 \times 10^{16}$ & & & 1000 & 20 & $\mathrm{~N}$ \\
\hline II-800 & (111) & & & 50 & $5 \times 10^{16}$ & 800 & 3600 & $\mathrm{~N}$ \\
\hline III & $(111)$ & 1 & $1 \times 10^{16}$ & 50 & $5 \times 10^{16}$ & - & - & $\mathrm{N}$ \\
\hline III-900 & (111) & 1 & $1 \times 10^{16}$ & 50 & $5 \times 10^{16}$ & 900 & 20 & Y R $(\mathrm{Si})$ \\
\hline $\begin{array}{l}\text { III- } \\
1000\end{array}$ & (111) & 1 & $1 \times 10^{16}$ & 50 & $5 \times 10^{16}$ & 1000 & 20 & $\mathrm{Y} \mathrm{R}_{\mathrm{p}}(\mathrm{Si})$ \\
\hline IV & $(100)$ & 1 & $1 \times 10^{16}$ & 50 & $5 \times 10^{16}$ & - & - & $\mathrm{N}$ \\
\hline IV-900 & $(100)$ & 1 & $1 \times 10^{16}$ & 50 & $5 \times 10^{16}$ & 900 & 20 & $\mathrm{Y} \mathrm{R}(\mathrm{Si})$ \\
\hline $\begin{array}{l}\text { IV- } \\
1000\end{array}$ & (100) & 1 & $1 \times 10^{16}$ & 50 & $5 \times 10^{16}$ & 1000 & 20 & $\mathrm{Y} \mathrm{R}(\mathrm{Si})$ \\
\hline $\mathrm{V}$ & $(100)$ & 1 & $1 \times 10^{16}$ & 10 & $5 \times 10^{16}$ & - & - & $\mathrm{N}$ \\
\hline $\mathrm{V}-800$ & $(100)$ & 1 & $1 \times 10^{16}$ & 10 & $5 \times 10^{16}$ & 800 & 3600 & $\mathrm{~N}$ \\
\hline V-900 & (100) & 1 & $1 \times 10^{16}$ & 10 & $5 \times 10^{16}$ & 900 & 20 & $\mathrm{~N}$ \\
\hline V-1000 & (100) & 1 & $1 \times 10^{16}$ & 10 & $5 \times 10^{16}$ & 1000 & 20 & $\mathrm{~N}$ \\
\hline
\end{tabular}


Figure 1. Bright field XTEM micrographs of (a) sample III-900 taken along [110] and (b) sample IV-900 along [011]. Diffraction pattern of the polycrystalline area on the right side of (a). The black arrow shows the end of range defects. The thin black lines in (a) and (b) represent the location of the a-Si/c-Si interfaces in the as implanted samples. The region between the dashed white lines in (b) indicates the position of cavities. The dashed black box indicates the zone magnified in (c).

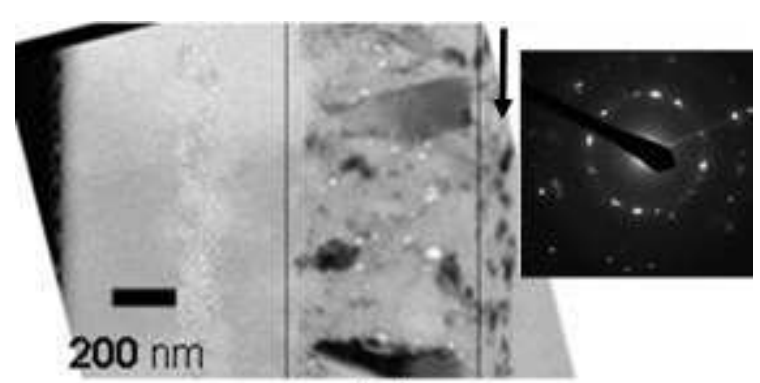

(a)

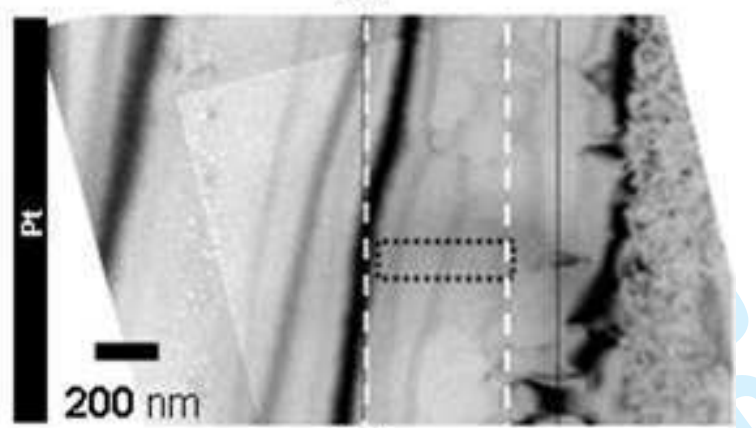

(b)

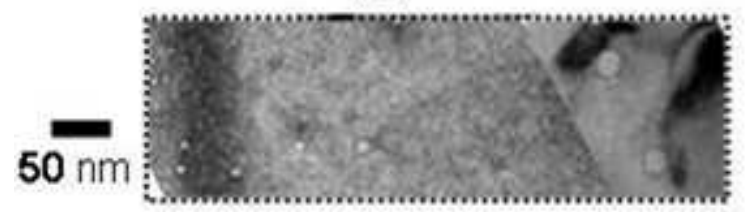

(c) 
Figure $2 .{ }^{3} \mathrm{He}^{+}$concentration profile calculated by TRIM simulation (continuous line), and measured by NRA in sample III (open circles) and III-1000 (full circles). The porous areas are $\mathrm{R}_{\mathrm{p}}(\mathrm{He})$ and $\mathrm{R}_{\mathrm{p}}(\mathrm{Si})$ are between the dashed and dotted lines, respectively. The polycrystalline zone extending from $700 \mathrm{~nm}$ to $1300 \mathrm{~nm}$ is represented by grey polygons.

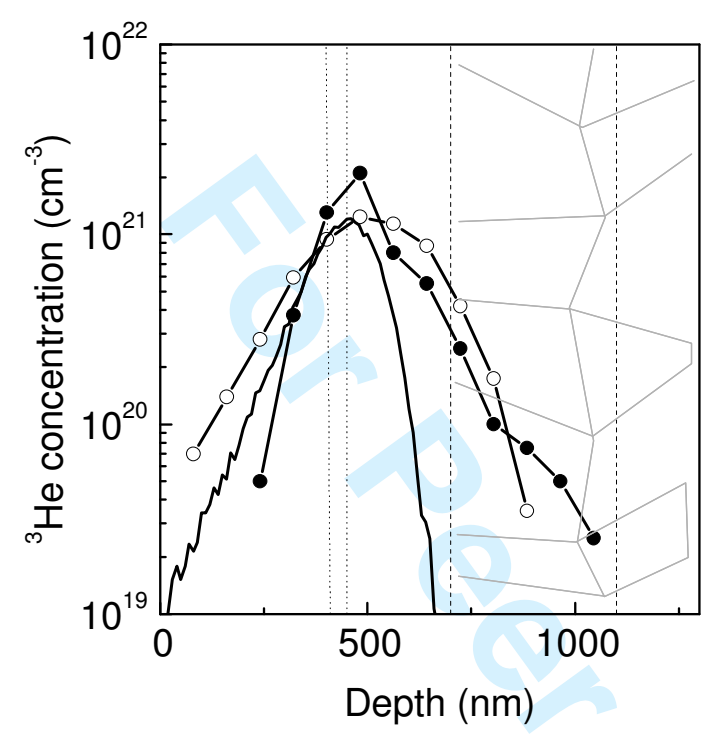


Figure 3. PAS measurements. (a) S(E) spectra obtained on II-800 (full squares) and on a virgin sample used as reference (open triangles); (b) $S(E)$ spectra obtained on samples III (open circles) and III-1000 (full circles). PAS spectrum obtained on a virgin sample is reported as a reference (open triangles); (c) S(W) for III, III-1000 and their reference. The trap signatures of divacancies $(0.012,0.558)$ and of cavities $(\mathrm{W}<0.01, \mathrm{~S}>0.578)$ are plotted.
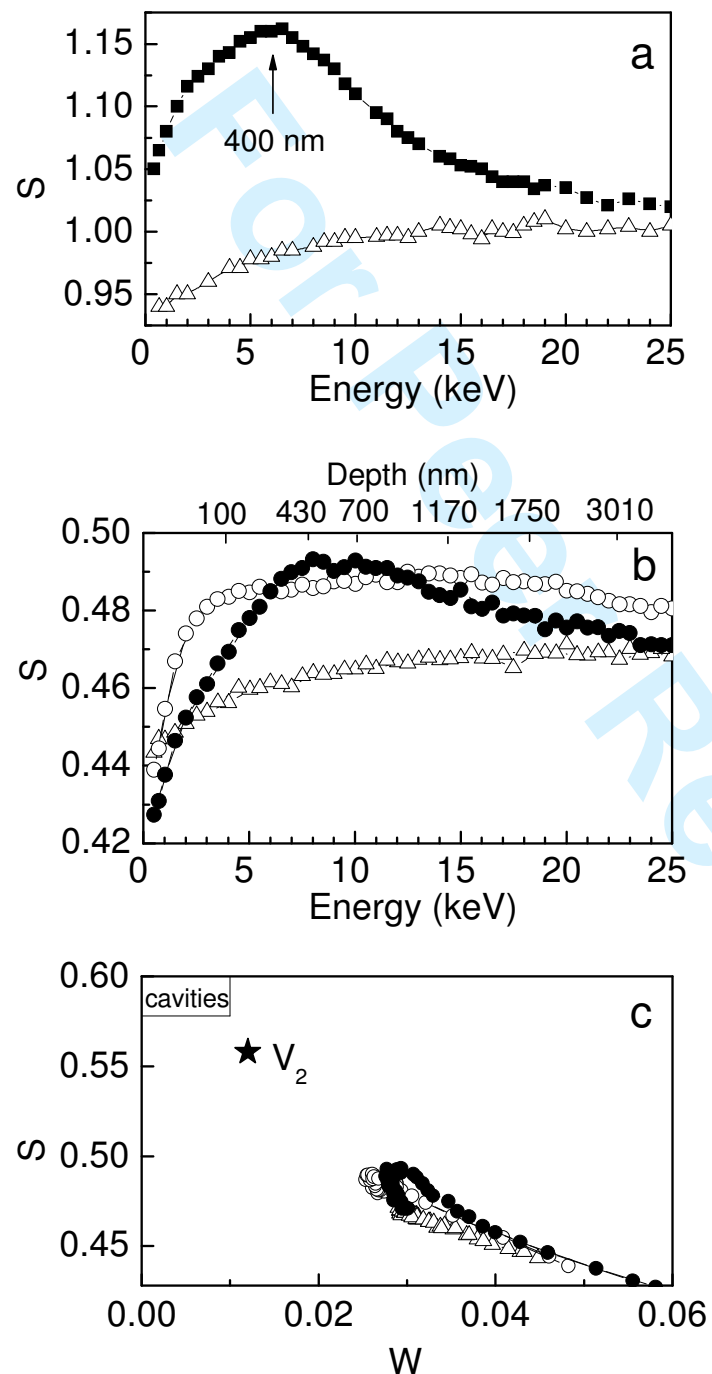